\title{
A "DPSIR" model for Mediterranean temporary ponds : European, national and local scale comparisons
}

\author{
I. Zacharias ${ }^{1}$, A. Parasidoy ${ }^{1}$, E. Bergmeier ${ }^{2}$, G. Kehayias ${ }^{1}$, E. Dimitriou ${ }^{3}$, P. Dimopoulos ${ }^{1}$
}

\begin{abstract}
${ }^{1}$ Department of Environmental and Natural Resources Management, University of Ioannina, Seferi 2, 30100 Agrinio, Greece, ${ }^{2}$ Department of Vegetation and Phytodiversity Analysis, Albrecht von Haller Institute of Plant Sciences, University of Göttingen, Untere Karspüle 2, D-37073 Göttingen, Germany.

${ }^{3}$ Institute of Inland Waters, Hellenic Centre for Marine Research, Anavyssos, Attiki, Greece.
\end{abstract}

\begin{abstract}
Mediterranean Temporary Ponds (MTPs) are priority habitats (Natura 2000) of great importance according to the European Legislation (Habitats Directive 92/43/EEC). They are being destroyed mostly because of public ignorance of their significant value. Today, MTPs are subject to high pressures from several human activities (agriculture, livestock, tourism etc.). In this work, the "Drivers-Pressures-State-Impacts-Responses" (DPSIR) model has been used, because it allows to evaluate the impact of the human socioeconomic pressure. We estimated the present condition of West Crete's MTPs, in order to propose management practices for their restoration. A comparison with the Greek and European MTPs is also developed.
\end{abstract}

Keywords : Mediterranean Temporary Ponds, MTP, protection, restoration, management plan, DPSIR, Crete.

\section{Introduction}

Mediterranean Temporary Ponds (MTPs) belong to the ephemeral freshwater ecosystems characterized by seasonal above-ground plant cover and habitats which are water-saturated or submerged only part, but for a sufficiently long period of the year (winter and spring). They present a significant variability in size, shape, depth, inundation period and duration of flooding, which is reflected by the diversity of their plant and animal communities. Seasonal pools, amphibic shorelines of permanent ponds, lakes and rivers and ephemeral flush habitats are the three habitat types distinguished according to relief, hydrology and climate (Deil 2005). In the most extensive review of the ephemeral wetlands at global scale, Deil (2005) refers to the differentiating gradients of the temporary ponds and emergent shorelines: a) water depth, periods of inundation and time of emergence as determinants of a characteristic vegetation zonation, b) soil depth and water storage capacity

\footnotetext{
* Corresponding author : E-mail : izachari@cc.uoi.gr
}

(on rock outcrops), c) duration of seepage water flow (on inselbergs), d) wave respectively ice scour intensity (in the shoreline habitat), e) frost-heaving intensity (in subarctic and oreotropical climates) and f) salinity (in endorheic playa lakes in arid and semi-arid climates).

Temporary ponds are common in Europe, North and South America, Australia and Africa (Fig.1a). They are recognized all over the world under different names (Cupular pools, Dayas, Poljes, dolines, ephemeral waters and Mediterranean temporary ponds) (Deil 2005, Zacharias et al. 2007). Mediterranean Temporary Ponds (MTPs) are included in Annex I of the Habitats Directive 92/43/EC, as a priority habitat type. Priority habitat types are those habitats in danger of disappearance and whose natural range falls mainly within the territory of the European Union (European Commission DG Environment 2007). In Europe, Ephemeral Wetland Vegetation types have been recorded in Spain, Portugal, Italy, France, United Kingdom, the Netherlands, Poland, Germany, Austria, Slowakia, Romania, Ireland, Norway, Hungary, Bosnia, Serbia, Lithuania and Greece and (Fig.1b). Bergmeier \& Raus (1999) summa- 

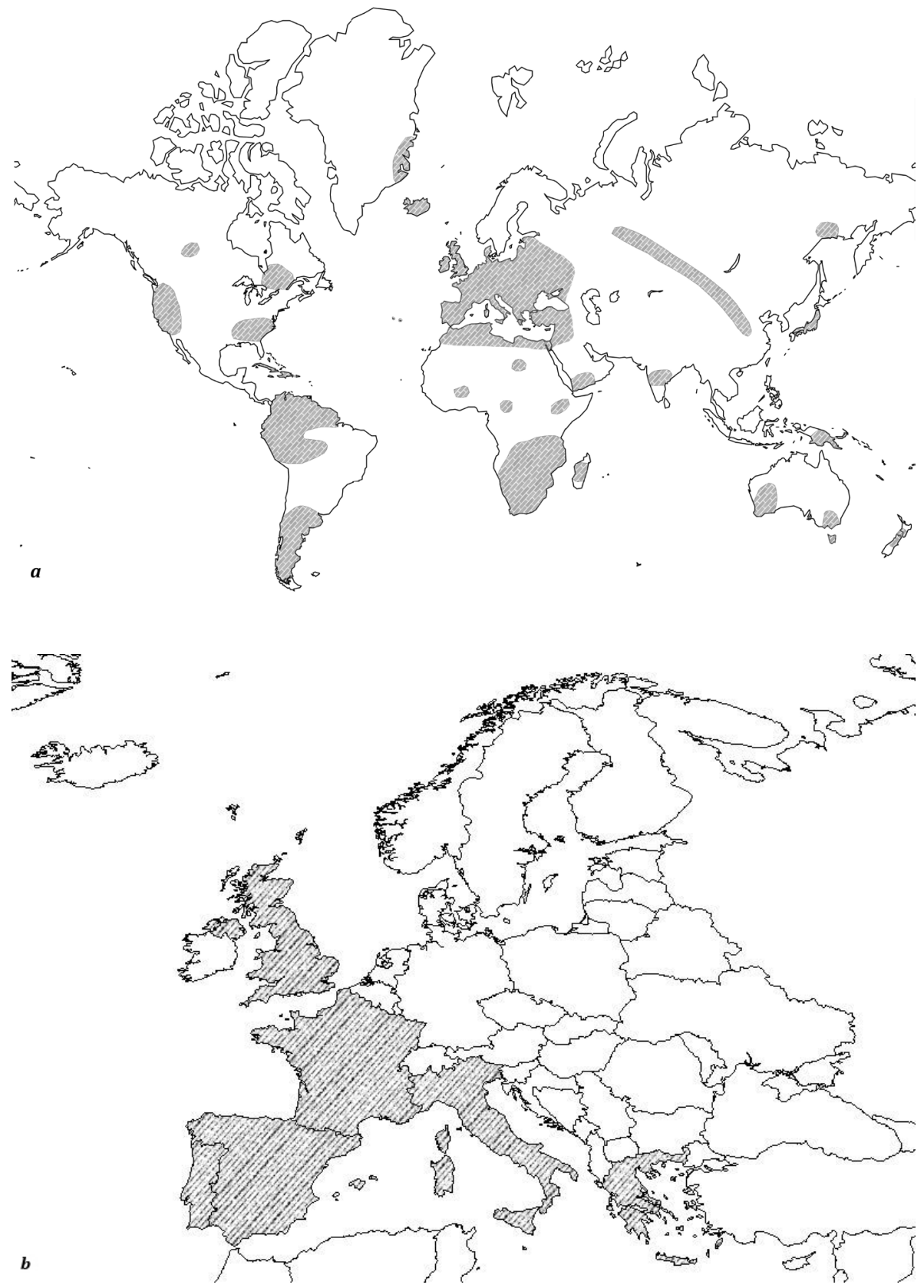

Fig.1. a) Global distribution of known MTPs, according to existing data (adapted from Deil 2005); b) European Union member states with MTP sites 


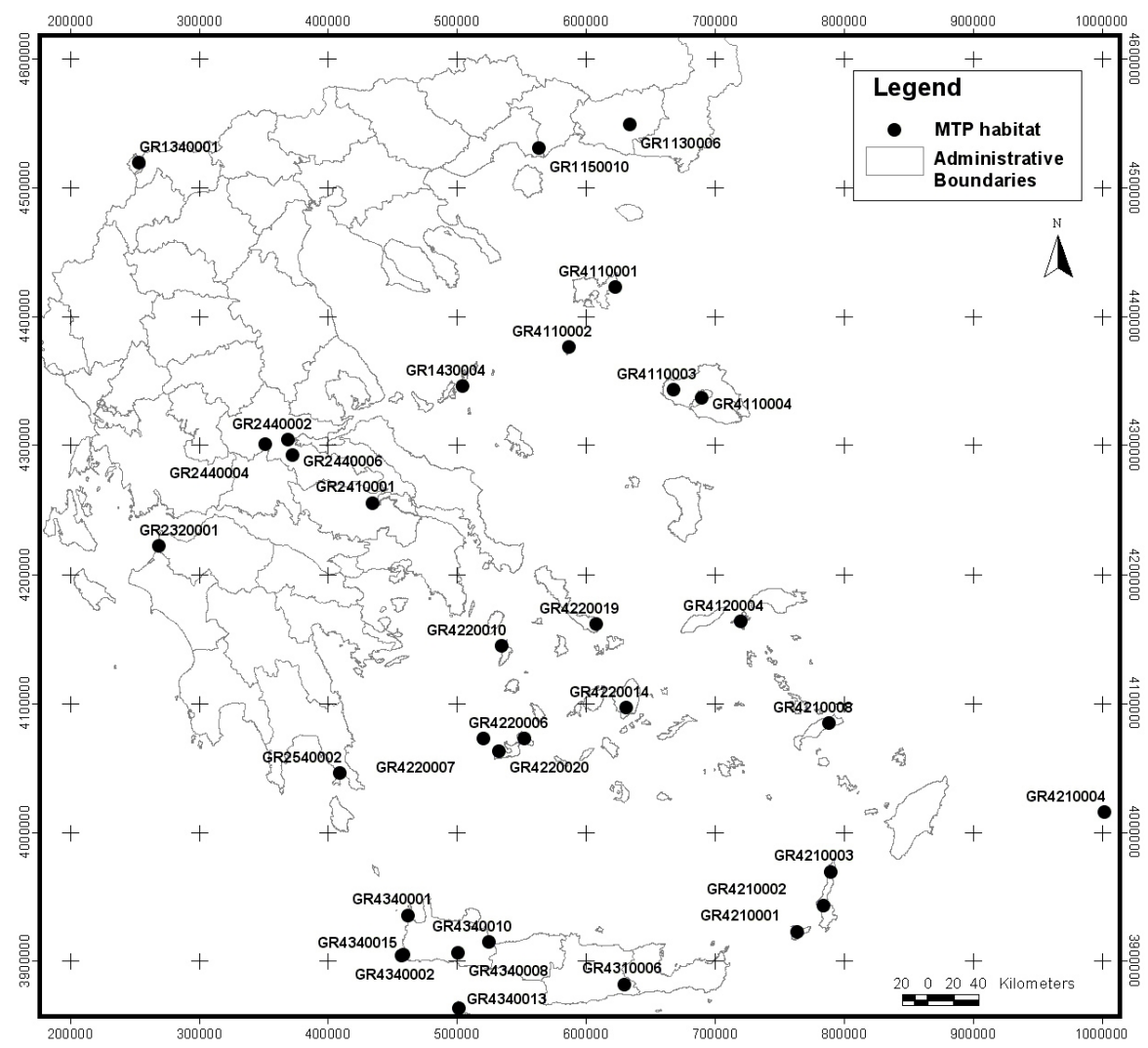

Fig.2. Greek MTP sites of the Natura 2000 Ecological Network.

rized the state of knowledge for the ephemeral wetland vegetation of Greece; further contributions come from Bergmeier (2001), Bergmeier \& Abrahamczyk (2008), De Bolòs et al. (1996), Oberdorfer (1952), Krause et al. (1963) and Sarika-Hatzinikolaou et al. (2003).There are many types of temporary ponds in the Mediterranean region, ranging from small copular ponds hollowed out in rocks (e.g. $<1 \mathrm{~m}^{2},<50 \mathrm{~cm}$ deep, Colle du Rouet, France) to almost permanent lakes, covering sometimes a quite large area (e.g. Teppe Rosse, Corsica, Zacharias et al. 2007).

According to Dafis et al. (1996), there are 48 Sites of Community Importance (SCIs) with the priority habitat type 3170 (MTP sites). Their distribution is given in Table 1 (Bergmeier \& Raus, 1999). Following the adaptations and corrections by the Mediterranean Biogeographical Seminars (until 2004), the Natura 2000
Ecological Network in Greece includes 34 MTP sites, distributed mostly on the Aegean islands (Fig. 2), where climatic conditions favor typical hydrological characteristics of the habitats (alterations between dry and wet periods) (Dimitriou et al. 2006). Only 11 of these sites are located in the mainland, with the remaining ones occurring in the Aegean islands. The island of Crete hosts the highest number of MTPs compared to any other region of the country $(20.5 \%)$.

The MTPs of Crete are the southernmost areas of European continent, where that habitat type occurs. Moreover, five areas contain different types of MTPs that support very interesting flora and fauna with some rare and endemic species (Dimitriou et al. 2006). Despite their great importance, the local population aggravates often them, usually due to ignorance of their value. 
The MTPs, due to their small surface area and their shallow depth, are very vulnerable habitats. During the last decades, they faced serious threats from anthropogenic activities (i.e. agricultural intensification, livestock watering, increasing number of tourists etc.), which possibly have led to degradation and in some cases to the extinction of these valuable ecosystems.

The aim of this paper was threefold: a) to assess the status of the Cretan MTPs, b) to develop management strategies for their conservation and restoration, and c) to compare the Greek and European MTP sites by using the Driver-Pressure-State-Impact-Response (DPSIR) approach. The DPSIR framework was adopted by the European Environment Agency (Smeets and Weterings, 1999), and progressively became widely applicable. The DPSIR analysis is a valuable tool, as it enables the parallel assessment of socio-economic and environmental parameters. Social and economic developments (Drivers) exert pressures on the environment and result in change in its state (physical, chemical and biological features). Furthermore, these changes lead to impacts on ecosystems, human health and natural processes and eventually these impacts generate political responses (Smeets \& Weterings 1999). Such responses can affect any element of the DPSIR parameters that then can create a feedback directly on the state of the environment or on the driving forces, hence on human activities. The DPSIR is widely used for the implementation of sustainable management of wetlands, because in such areas the major drivers derive from anthropogenic activities (Lin et al. 2007).

\section{Study area}

The MTPs in the island of Crete are chiefly located in the Prefecture of Chania (Fig.3). The five sites of the study area belong to the Natura 2000 protection network.

Gavdos Island: The island of Gavdos (GR4340013) is the southernmost boundary of Greece and thus of Europe. In Gavdos there are almost 100 rock pools dispersed in 5 sites, that are small karstic rocky depressions with a cuppy form (rock pools - size $<1 \mathrm{~m}^{2}$, deep $10-50 \mathrm{~cm}$ ). They concentrate the rain water and their usage in the past was the watering of livestock. This specific type of MTPs located in Gavdos are unique in the area of South Aegean (Dimitriou et al. 2006).

Drapano (North Eastern Coasts) - Georgioupolis Beach - Kourna Lake: Kourna Lake (GR4340010) is located in the North of Crete, at the boundary the Pre- fectures of Chania and Rethimno. There is a pond in the North side of the lake, near the coastline, which is a shallow depression which flooding regime is directly related to the fluctuation of the lake's level.

Elafonisos (from Chrysoskalittisa until Krios Cape): Elafonisos (GR4340002) is located in Southwestern Crete, and there are more than 16 ponds in this region. The ponds in this habitat are shallow depressions in poljes filled up with clay and sand.

Imeri and Agria Gramvousa - Tigani and Falasarna - Pontikonisi: Falasarna (GR4340001) is located in the West coast of the Chania Prefecture. There are 3 ponds and in its South part, which were used to form a unified pond prior to the construction of a road along the coast. These ponds contain brackish water and are located in sand dunes. From all the different types of MTPs in Crete, only these ponds are related to groundwater fluctuation levels.

Lefka Ori (White mountains) (GR4340008): The plateau of Omalos is situated in the center of the Prefecture of Chania and there is one relatively large pond located in the southwest side of the plateau at an altitude of $1050 \mathrm{~m}$. Omalos pond is a rather deep depression (up to $1.7 \mathrm{~m}$ ) with a fine sediment substrate.

During the last decades, the island of Crete had a major financial development in the field of agriculture, as well as in tourism. These two aspects, in combination with the livestock activity, constitute the three main drivers that cause various problems to MTPs. Agricultural activities such as the expansion of greenhouses and livestock breeding, increase the amount of nutrients reaching the ponds while water over-exploitation for irrigation and animal watering increase the pressures. In summer, the number of visitors increases significantly and contributes also to the pollution of MTPs water (there are no waste water treatment plants in the study areas), while the demand for developmental infrastructure (roads, hotels, etc.) in combination with touristic activities generates impacts on the soil of the ponds (extraction, consolidation, etc). Finally, during the last years the amount of rainfall decreased, with an important adverse effect on the hydroperiod of these wetlands.

\section{Methodology}

The DPSIR approach is a development form of the PSR (Pressure - State - Response) framework developed by OECD (1993). The European Environmental 


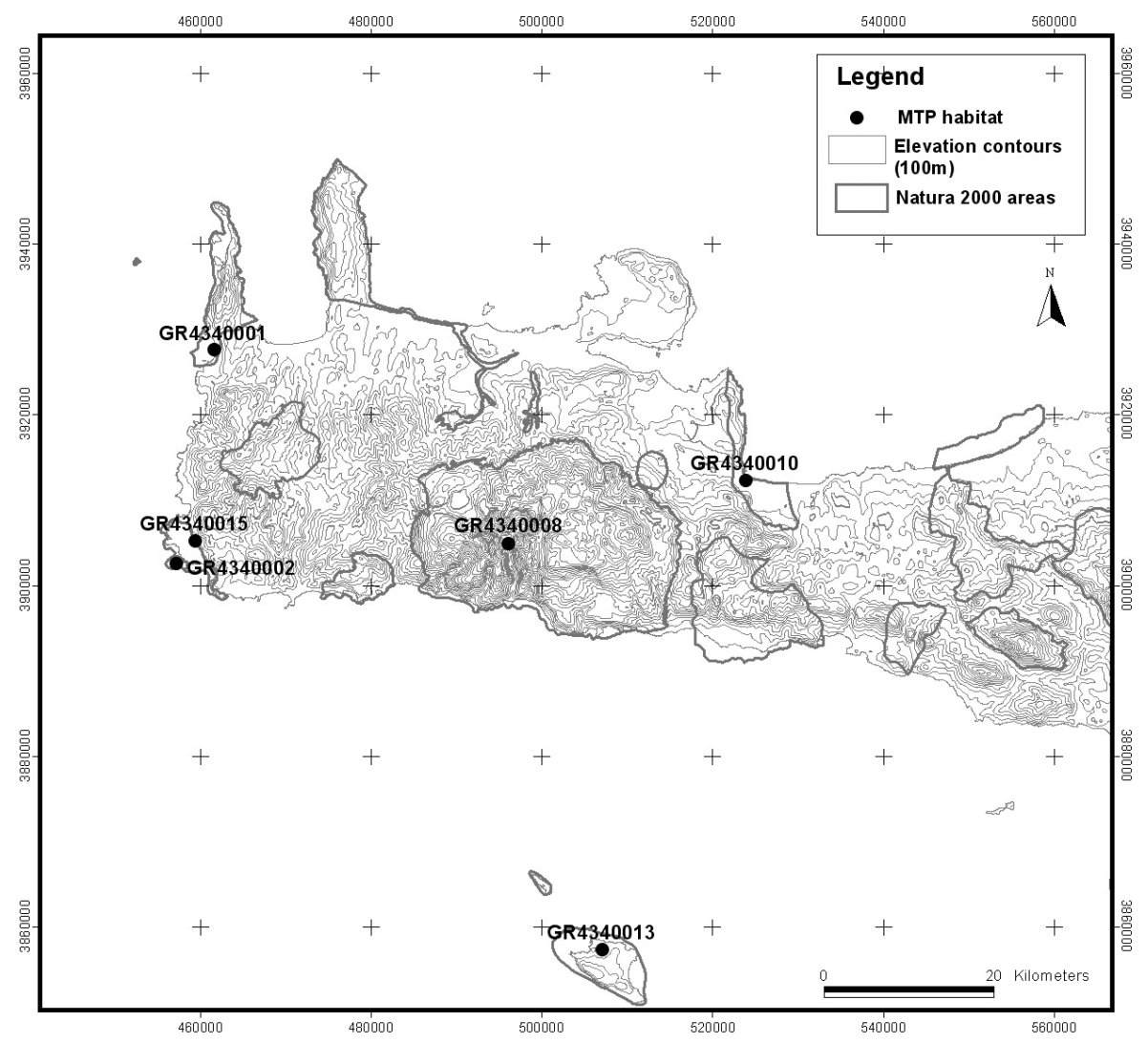

Fig. 3. Location of the MTPs of Crete

Agency (Smeets \& Weterings 1999) recently proposed the DPSIR for the implementation of the Water Framework Directive 2000/60/EC. This conceptual framework is used to organize information about the state of the environment and the relations between human activities and possible environmental changes. This approach is based on the concept of causal links that start with the human activities (driving forces) exerting pressures on the environment, which then change the quality and the quantity of natural resources and finally lead to societal responses. The DPSIR analysis uses indicators (sets of physical, biological or chemicals variables) in order to provide to the policymakers clear and specific information on: 1) the driving forces, 2) the resulting environmental pressures, 3) the state of the environment, 4) impacts resulting from environmental changes, and 5) the possible societal response (Smeets \& Weterings 1999, Walmsey 2002, Elliot 2002, Kristensen 2004, Pirrone et al. 2005). The DPSIR for the European MTPs is illustrated in Fig. 4 (Grillas et al. 2004, Stamati and Nikolaidis 2006, Zacharias et. al. 2007).

For this paper, the DPSIR framework has been used in order to detect the driving forces and their pressures in the MTPs of Crete, assess their state, identify the associated impacts and eventually, propose the necessary responses in order to restore, protect and preserve these valuable habitats. The development of the DPSIR model incorporated here a profound analysis of the MTPs conditions and of the local social characteristics. Thus, the drivers can be defined as the elements in the broader area of the MTPs that create the pressures to the ponds while the pressures are the causes for the 
habitat's status alteration. Additionally, the impacts are the effects of changes in the state of these priority wetland habitats and the responses are the management strategies that the policy-makers make to restore these habitats.

Our data originated from the project "Actions for the conservation of Mediterranean Temporary Ponds in Crete", LIFE04NAT/GR/000105. They have been used in combination with data from similar studies that have been conducted elsewhere in Europe. Additionally, information about the European MTPs vegetation, socioeconomic and environmental management strategies, pressure indicators and associated impacts have been collected from relevant databases and relevant bibliographic sources. The aforementioned Life project is a multidisciplinary research effort focusing on the MTPs of Crete, and aims at recording detailed data regarding the habitats' geological, hydrological, ecological and socio-economic conditions. The priority is to identify the causal link between anthropogenic activities and the habitats' degradation, and to achieve the restoration of the MTPs in a good ecological condition that existed prior to the observed impacts. Thus, this particular study will use the above-mentioned information to clarify the pressure - impact relationship at each site by using the DPSIR approach, examine the underline socio-economic drivers and suggest management and restoration practices. The same approach will be attempted for all the European MTP habitats for which the necessary data exist and a comparison of the different drivers, pressures and responses along the geographical gradient will be realized. This will allow the identification of the effects that different drivers and responses have on the habitat status and will facilitate the optimization of the MTPs management at a European level.

\section{Results and discussion}

The data collected for the implementation of the DPSIR framework for the five Cretan MTP sites were related to the hydrology, the geology, the climatic conditions, the ecological status and also the chemical features of the ponds. These features combined with information about the pressures and the threats that the MTPs face were used, as well as socio-economic data and data about the study area. In the following sections there is a presentation of the DPSIR analysis for the MTPs of five differents sites in western Crete (Gavdos, Kourna, Elafonisos, Falasarna and Omalos). In these analyses the relationship cause - effect between the socio-economic drivers (human activities) and the environmental impacts is clearly established.

Gavdos island: The dominant activities that threaten the rock pools of Gavdos are livestock and secondarily tourism (Table 1). Today tourism in the area illustrates an increasing developmental trend, but it is mostly characterized by the absence of planning, and arbitrary building and/or roads constructions without prior impact assessments of threats to MTPs, especially in the coastal zone. Livestock watering demands significant water quantities, which leads to the overexploitation of pond waters, affecting their hydroperiod. In order to prevent evaporation from the ponds, farmers cover the deeper ones with stones to maintain water for longer periods, but this practice may have negative consequences for the development of the characteristic MTP vegetation. Additionally, random destruction of the small ponds constitutes a serious threat to the most vulnerable ecosystems (Table 1). The results of the Life project monitoring indicated that even though water quality in the ponds is good on average, the nutrients show temporal fluctuations. The concentrations of $\mathrm{NH}_{4}$ correspond to a moderate state, and the nutrient loads have relatively low concentrations in this area due to the small number of livestock. The long-term decrease in the amount of rainfall causes reduction of the pond's hydroperiod and alters the ecological characteristics of the pond. For the conservation of the MTPs, the decrease of existing threats could be achieved by contacting and informing the local population about the values and services of the MPT habitat. Monitoring the number of flocks in the area and the water consumption is also necessary.

Kourna lake: In the area of Kourna lake the main drivers are tourism and agriculture (Table 1). The intensification of agriculture with the extensive use of pesticides and fertilisers enhanced pollution levels in the lake, which subsequently polluted the aquifer as well. The eutrophication level of the lake water fluctuates seasonally but there is a direct link between agricultural practices, water pollution, and trophic status of the lake. Moreover, agricultural intensification in the catchment area supports the expansion of the shrubberies (Vitex). As the water level of the lake lowers because of water abstractions for irrigation, the hydroperiod of the ponds is strongly affected. The MTP and the lake are submitted to the pressure from the overgrazing of flocks of geese, which prevent the growth of the typical MTP vegetation and rare species. Tourism in the broader area is continuously increasing. During the summer months many activities that disturb the habitat's fauna (i.e. sea bicycles) take place near the lake. No waste water treatment plants exist, and all the urban pollution loads 
Table 1. DPSIR analysis for the Cretan MTPs

\begin{tabular}{lll}
\hline $\mathrm{D}$ & Livestock \\
& Tourism \\
& Agriculture
\end{tabular}

P Livestock watering

Water pollution

Pond covering with stones

Arbitrary construction

Climate change

Overexploitation of water

Intensification of land use in catchment

Overgrazing

Pollution of soil and MTP surroundings

Expansion of greenhouses and cultivations

Wastes and sewages

Soil excavation

S Nutrients - Temporal fluctuation

Ammonia

Nitrates

Nitrites

Organic salts \& phosphorous

Occurrence of rare habitat-specific species

Conservation status

Total phosphorus

\begin{tabular}{|c|c|c|c|c|}
\hline Gavdos & Kourna & Elafonisos & Falasarna & Omalos \\
\hline $\mathrm{V}$ & & & & $\mathrm{V}$ \\
\hline \multirow[t]{2}{*}{$\mathrm{V}$} & V & V & V & \\
\hline & $\mathrm{V}$ & V & V & \\
\hline \multirow[t]{2}{*}{$\mathrm{V}$} & & & & V \\
\hline & V & & & $\mathrm{V}$ \\
\hline $\mathrm{V}$ & $\mathrm{V}$ & $\mathrm{V}$ & & \\
\hline \multirow[t]{7}{*}{ V } & & V & & \\
\hline & $V$ & & & \\
\hline & V & & V & \\
\hline & V & V & V & V \\
\hline & & V & V & \\
\hline & V & & $\mathrm{V}$ & \\
\hline & & V & & \\
\hline \multirow{3}{*}{$\begin{array}{l}\mathrm{V} \\
3\end{array}$} & $\mathrm{~V}$ & V & V & V \\
\hline & 2 & 2 & 3 & 2 \\
\hline & 2 & 3 & 3 & 2 \\
\hline 1 & 2 & 3 & 3 & 1 \\
\hline \multirow[t]{2}{*}{2} & 3 & 3 & 4 & 2 \\
\hline & $\mathrm{V}$ & V & t & $\mathrm{V}$ \\
\hline \multirow{2}{*}{ V } & & & & \\
\hline & V & V & V & \\
\hline \multirow{4}{*}{ V } & $\mathrm{V}$ & V & V & \\
\hline & $\mathrm{V}$ & & & \\
\hline & & V & V & \\
\hline & & & V & \\
\hline \multirow[t]{2}{*}{ V } & V & V & V & $\mathrm{V}$ \\
\hline & V & & V & \\
\hline \multirow[t]{6}{*}{ V } & & V & & V \\
\hline & V & $\mathrm{V}$ & & \\
\hline & & $\mathrm{V}$ & $\mathrm{V}$ & \\
\hline & & V & $\mathrm{V}$ & \\
\hline & & & V & \\
\hline & & & V & \\
\hline V & V & V & V & V \\
\hline
\end{tabular}

I Vegetation destruction

Eutrophication

Early drainage

Habitat destruction

Wastes and sewages

Alteration/reduction of hydroperiod

Reduction of lake's water level

Landscape and land use change

Overexploitation of water sources / aquifer

R Informing the public (incl. authorities)

Watering construction

Farming without chemical fertilizers and

pesticides

Monitoring of grazing

Sewage disposal system construction

Prohibition of soil perturbations

Practice and impose legal means

Practice local land and property register

Restoration and monitoring of hydrological

dynamic

Promotion new techniques for soil

decontamination

Monitoring water consumption and vegetation 
of the area eventually end up in the lake. The touristic constructions around the lakeshore occurred without appropriate planning and the artificial embankments have destroyed a significant part of the wetland habitats. There are high accumulations of dissolved elements in their soil, the water quality regarding the nitrites is characterized as in good condition. The nitrates have also relatively low concentrations, and the water quality status regarding the total phosphorus is moderate. The pond presents a relatively high accumulation of $\mathrm{NH}_{4}$, which is due to the mineralization of the organic matter (i.e. waste water and use of fertilizers). Also, temporal fluctuations of nutrients in the pond are very high. The conservation condition of this habitat during the last years seemed to be steadily degraded without showing indications for further distortion. In order to reduce the problems caused by almost all drivers, it is fundamental to contact and inform the public. The cultivations located near the lake catchment should shift to low impact activities by applying environmentally-friendly practices (no chemical fertilizers and pesticides). The shrubbery have to be controlled, with the cutting the individuals of Vitex agnus-castus in a limited area around the MTPs. Moreover the construction of sewage and solid waste infrastructure such as a collection and treatment system will offer a final solution to the urban pollution problem. Overgrazing by geese should to be controlled, by reserving and fencing a specific area for geese grazing.

Elafonisos: In this area, the main driver is agriculture (Table 1). During the last decade there has been a great expansion in the number of greenhouses, combined with intense use of chemical fertilizers and pesticides, as well as with the disposal of wastes from the greenhouses (used nylons, hydroponic materials, pesticides packages, etc.). Moreover, the intensification of agriculture during the last years has led to the loss of at least 2-3 ponds, constituting a continuous a serious threat directly linked to changes in land use (extension of the agricultural areas). Additionally, soil extraction for the construction of greenhouses (it is used as a substrate) resulted in the alteration of the landscape and of the hydrological status of ponds (Table 1). In Elafonisos, tourism also showed fast development and there is still a strong pressure for creating large scale infrastructures (hotels, restaurants, etc). The climate change in the broader area will strongly affect the hydroperiod in the forthcoming 50-100 years since the annual amount of rainfall may undergo a $20 \%$ decrease (according to an IPCC scenario) which will change the ecological status of the habitats. The ecological assessment of the 16 studied ponds indicates a good status.
The organic salts have low concentrations, while the nitrates are in relatively low levels and the nitrites are in moderate concentrations. Total phosphorus accounts for a good state and the load of nutrients shows very high temporal fluctuations, especially when the ponds are almost drained. Moreover, $\mathrm{NH}_{4}$ concentrations increase significantly through the mineralization of the organic matter (i.e. sheeps' manure). During the last six years the ecological conditions of such habitat types were degraded from good to medium, and therefore responses (measures) should be triggered (e.g., prohibition of uncontrolled soil extraction). For this purpose, a site specifically designed for sediment collection should be established in cooperation with the Municipality of Inachorio. The public should be informed about the importance of MTPs, in order to avoid direct habitat destruction through activities such as $4 \times 4$ sport driving. Furthermore, the implementation of local land use and ownership cadastre is necessary to avoid further expansion of the greenhouses. Monitoring of the grazing livestock could serve the optimum management practices and thus the decrease of the associated impacts.

Falasarna : In the area of Falasarna the major drivers that exert pressure on the MTPs is agriculture, and secondarily tourism (Table 1). The use of chemical fertilizers and pesticides in combination with their wastes create water pollution problems to the MTPs, and eutrophication levels raise. Moreover, the local aquifer supplies the pond water storages while its overexploitation for irrigation purposes leads to the decrease of the habitat's hydroperiod. Additionally, over-pumping of the groundwater causes seawater intrusion and therefore increases in the salinity of the pond water (brackish water). In this area there are no wastewater treatment plants while the soil receives pressures from the greenhouses and roads construction. During summer months, the touristic activity, which is well developed in the area of Falasarna, enhances the pollution due to untreated solid waste and sewage disposal. Falasarna ponds present the maximum salinity compared to the rest of Crete MTPs due to the proximity in the seashore (less than $50 \mathrm{~m}$ ) and the seawater intrusion problem. The $\mathrm{NH}_{4}$ presents high concentrations, because of the mineralization of the organic matter. The nitrate and nitrite levels in the pond behind the 1st seashore dunes zone (pond 1) are relatively low (good status), whereas in the pond near the sea (pond 2) they are high (bad state). The temporal fluctuations in nutrients are very high in this MTP site (Table 1). Also, during the last six years the conservation status has declined from moderate to bad, mainly as a result of agricultural intensification. In order to decrease the pressures on the MTPs in this area, a 
strong informative campaign should be conducted. Such a campaign should target specific groups to address the problems created by the greenhouses. Moreover, local assistance should be provided to help local populations to adapt to the recent National and European legislation (law enforcement facilitation for Habitat and Birds Directives, polluter pays principle, etc.). Also, the local cadastre system should be developed, in order to control the expansion of greenhouses and plan optimum land uses for both environmental preservation and developmental activities. Furthermore, monitoring and restoration of the MTPs hydrologic dynamics and the promotion of new techniques for the soil decontamination in greenhouses are necessary to eliminate water quality and quantity related impacts.

Omalos : The dominant driver for the MTP on the Omalos plateau is livestock breeding (sheep), resulting in trampling and overgrazing of the vegetation (Table 1). The concentration of large number of animals around the pond especially during the summer period, when no alternative source of water exist, leads to high nutrient inflow and loss of the typical MTP vegetation. Agriculture in the area of Omalos is not so intense, due to the high altitude of the area $(1050 \mathrm{~m}$ above sea level) that create unfavorable conditions for most crop types and a lack of water during summer time. The MTP is surrounded by two roads and the construction works have probably affected the size and the shape of the pond. In the pond of Omalos, the concentrations of nitrates and nitrites are relatively low (good status), total phosphorus is also at low levels while organic phosphorus is relatively elevated due to livestock grazing and watering in the area. Furthermore, $\mathrm{NH}_{4}$ concentrations are high due to the mineralization of the organic matter (livestock manure). Rare wetland species occur in this MTP, some of which are not found elsewhere in Crete. Thus, vegetation in this site should be annually monitored, as well as the number of flocks and water consumption in order to specify relevant management practices. Furthermore, the construction of animal watering infrastructures should lead to the restoration of the hydroperiod and water quality, since the livestock will not use the MTP for watering with the current intensity anymore. Finally, the local population should be informed about the value of that habitat type in order to prevent accidental destructions.

\section{The European MTPs}

Mediterranean Temporary ponds are encountered in many European countries in the EU (Spain, Italy,
Greece, France, Portugal and England). They share common faunistic and floristic characteristics, as well as similar threats and impacts. In the Mediterranean region human influences were always present, but nevertheless MTPs' high biodiversity has been preserved for centuries in equilibrium with human activities (Beja \& Alcazar 2003, Grillas et al. 2004, Rhazi et al. 2001). There is no current research enabling the decline of temporary ponds to be measured (Grillas et al. 2004), but as agriculture and urban development play an increasing role in the Mediterranean region, numerous sites with temporary ponds are in danger of degradation (Beja \& Alcazar 2003, Blaustein \& Schwartz 2001, Brendonck \& Williams 2000, King 1996).

Increased urbanisation in the Mediterranean region has led, through housing or road development projects, to the extinction of numerous temporary ponds, which also face less obvious threats. Water from the ponds is often used for various purposes, such as irrigation of agricultural land, watering of livestock and domestic use. This can occur by direct extraction or by pumping close to the ponds, frequently resulting in the premature drying off of the ponds (Brendonck \& Williams 2000, Serrano \& Serrano 1996). Artificial drainage of the pond catchment for human purposes in the dry season also shortens the inundation period, which is known to affect organisms that depend on the aquatic phase of the ponds for their reproduction and development (e.g. amphibians and Odonata species), (Grillas et al. 2004, Serrano \& Serrano 1996). Pollution levels of temporary ponds are generally increasing by intensified agricultural activities with extensive use of pesticides and fertilizers and by domestic and industrial waste and airborne pollutants (Everts 1997, Lahr 1997).

Comparing the DPSIR scheme for Cretan, Greek and European MTPs based on literature references, the Natura 2000 network database, and Life-Nature results, several common aspects and some important differences have been found. In particular, the drivers are almost identical at all scale levels (regional, national, European), apart from urbanization which is not the relevant in Crete (Touristic developments are considered separately). Common pressures observed at all three levels include water overexploitation, overgrazing and destabilization of the hydroperiod due to climate change (Table 2). Cultivation expansion and infrastructural constructions (e.g., roads) are recorded at many Greek sites due to the lack of a cadastre system, and in some cases because of the absence of basic infrastructure. The water quality and the ecological status, including plant community composition and occurrence of characteristic species are the main MTP factors affected 
Table 2. DPSIR analysis for the Cretan, Greek and European MTPs

\begin{tabular}{|c|c|c|c|c|}
\hline & & Crete & Greece & Europe \\
\hline \multirow[t]{4}{*}{$\mathbf{D}$} & Urbanization & & $\mathrm{V}$ & $\mathrm{V}$ \\
\hline & Agriculture & V & $\mathrm{V}$ & $\mathrm{V}$ \\
\hline & Livestock & $\mathrm{V}$ & $\mathrm{V}$ & $\mathrm{V}$ \\
\hline & Tourism & $\mathrm{V}$ & $\mathrm{V}$ & $\mathrm{V}$ \\
\hline \multirow[t]{10}{*}{$\mathbf{P}$} & Land use change & V & & $\mathrm{V}$ \\
\hline & Water overexploitation & $\mathrm{V}$ & V & $\mathrm{V}$ \\
\hline & Overgrazing & V & V & V \\
\hline & $\begin{array}{l}\text { Increase of wastes, wastewaters } \\
\text { and sewages disposals }\end{array}$ & & & $\mathrm{V}$ \\
\hline & Recreational activities & & V & V \\
\hline & Climate change & V & $\mathrm{V}$ & $\mathrm{V}$ \\
\hline & Cultivation expansion & V & $\mathrm{V}$ & \\
\hline & Constructions, roads, etc. & V & V & \\
\hline & Pollution & $\mathrm{V}$ & $\mathrm{V}$ & \\
\hline & Soil excavation & V & & \\
\hline $\mathbf{S}$ & Water quality & $\mathrm{V}$ & $\mathrm{V}$ & $\mathrm{V}$ \\
\hline \multirow{5}{*}{ I } & Ecological status & & & \\
\hline & Eutrophication & $\mathrm{V}$ & $\mathrm{V}$ & $\mathrm{V}$ \\
\hline & Hydrological disturbances & V & V & V \\
\hline & Habitats/species loss & V & $\mathrm{V}$ & $\mathrm{V}$ \\
\hline & $\begin{array}{l}\text { Soil erosion } \\
\text { Microbial / organic pollution (Wastes and sewages) }\end{array}$ & V & $\mathrm{V}$ & $\mathrm{V}$ \\
\hline \multirow[t]{8}{*}{$\mathbf{R}$} & Public awareness & V & V & V \\
\hline & Reduction of pollution sources (case specific) & V & V & V \\
\hline & Ecological monitoring & $\mathrm{V}$ & & $\mathrm{V}$ \\
\hline & Restoration of hydroperiod & & & $\mathrm{V}$ \\
\hline & Livestock \& vegetation monitoring & V & & \\
\hline & Co-operation with stakeholders & & & $\mathrm{V}$ \\
\hline & Watering constructions & $\mathrm{V}$ & & \\
\hline & $\begin{array}{l}\text { Implementation of management } \\
\& \text { conservation measures }\end{array}$ & $\mathrm{V}$ & & $\mathrm{V}$ \\
\hline
\end{tabular}

by the above mentioned pressures at all spatial scales (Table 2).

The impacts on the MTPs (Table 2) are common at all spatial scales. The most important ones include: eutrophication, hydroperiod destabilization, organic pollution and habitat loss. The only impact that is only observed in the Cretan and Greek sites but not in the European ones is organic pollution from agricultural waste (effect of sewage waters, disposal of empty pesticide bins and tanks, plastic and other materials from greenhouses, disposal of crop surplus). Part of this situation is due to the lack of waste water treatment plants in many countryside municipalities and villages in Greece, which leads to significant water quality degradation.

The responses implemented to tackle the pressures and minimize the impacts on the MTPs illustrate sig- nificant differences between the studied scales. Public awareness is a response applied in all the cases while elimination of pollution sources on a site-specific basis has been recorded in many European sites and in Crete Island through a Life-Nature project. Restoration of the hydroperiod has not yet been applied in the Greek sites but after the Water Framework Directive enforcement, several water resources management plans will be implemented, that will consider the environmental water demands. Grazing capacity studies and watering infrastructure as response measures are relatively new approaches in Crete island, due to the intensity of livestock breeding in the area. However, the efficiency of this approach has not been assessed yet. Implementing management and conservation measures focused on the MTPs is a necessary but rarely applied effort at 
most sites. Up to now, specific management plans for targeted habitat have been designed and applied in a limited number of cases under the framework of LifeNature projects in Crete, and in few European sites. Thus, after comparing the Greek and European MTP DPSIR schemes some important differences arose from specific points such as the lack of cadastre system and adequate waste water treatment plants in Greece. These concerns are usually not observed in other European sites, while the responses at the national level are very limited compared to the EU level. causing them are agriculture, livestock breeding, urbanization and tourism (Rhazi et al. 2001, Dimitriou et al. 2006, Zacharias et al. 2007). These habitats are vulnerable to pressures, mainly due to their small surface area (Grillas et al. 2004). Most of the countries along the Mediterranean Sea were applying subsidence farming practices and livestock activities during the previous decades. During the last 20 years agricultural intensification occurred with the expansion of cropland areas and greenhouses, as well as with the extensive use of pesticides and chemical fertilizers. All these pressures

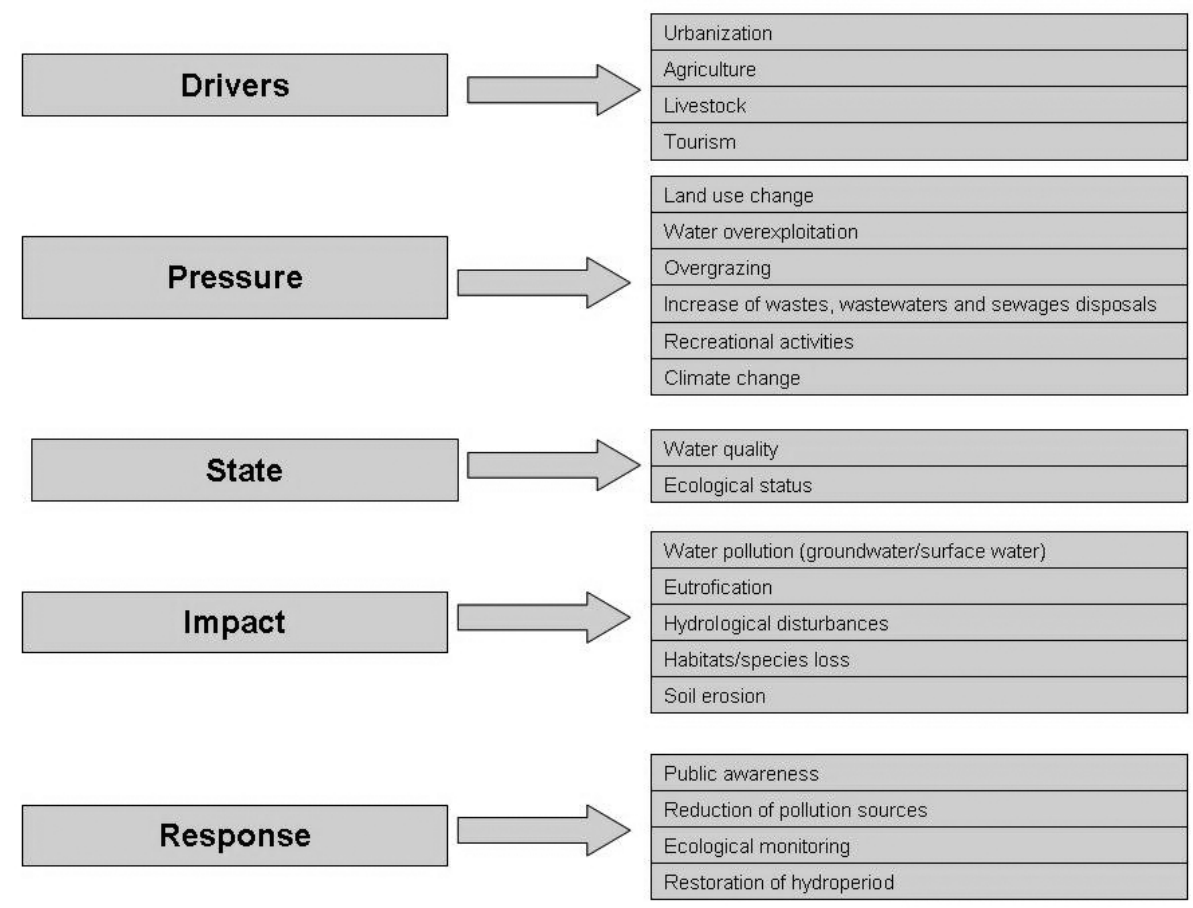

Fig. 4. DPSIR analysis for European MTPs sites

\section{Conclusions}

Summarizing our DPSIR analyses conducted for each MTP sit,e a generalized DPSIR model has been concluded for the Cretan MTPs (Fig.5). Comparing the DPSIR analyses for Cretan (Fig.5), Greek (Fig.6) and European MTPs located mainly in the Mediterranean region (Fig.4), the similarity of threats becomes apparent. The anthropogenic pressures in the Mediterranean area are very intense and the main human activities lead to the increase of water pollution in the ponds and in the aquifers, soil depletion due to excavation for the construction of greenhouses, and land use alterations (Bergmeier \& Abrahamczyk 2008). The livestock grazing and watering supplies nutrients to the ponds often lead to eutrophication, altering the composition of the vegetation. The MTPs undergo water overexploitation through abstractions for livestock watering and crop irrigation. 


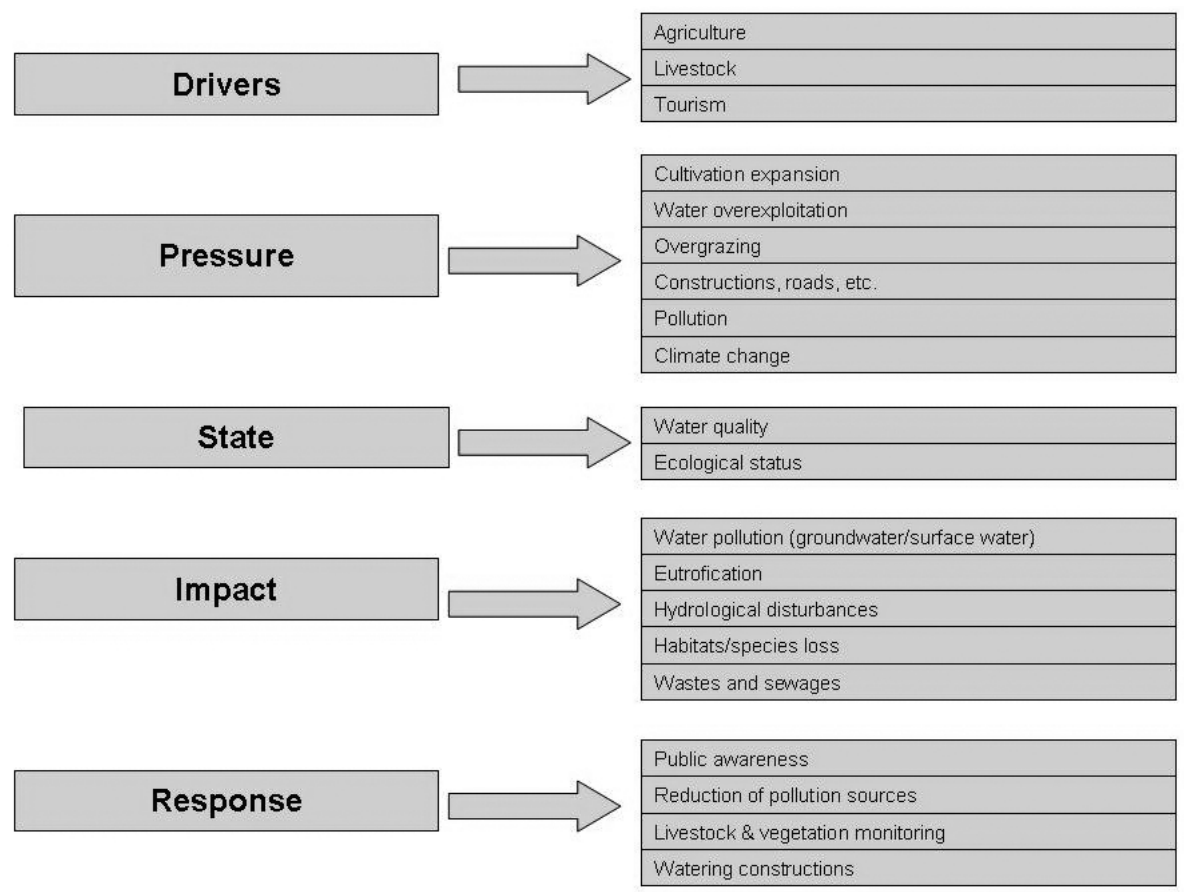

Fig. 5. DPSIR model for Cretan MTPs

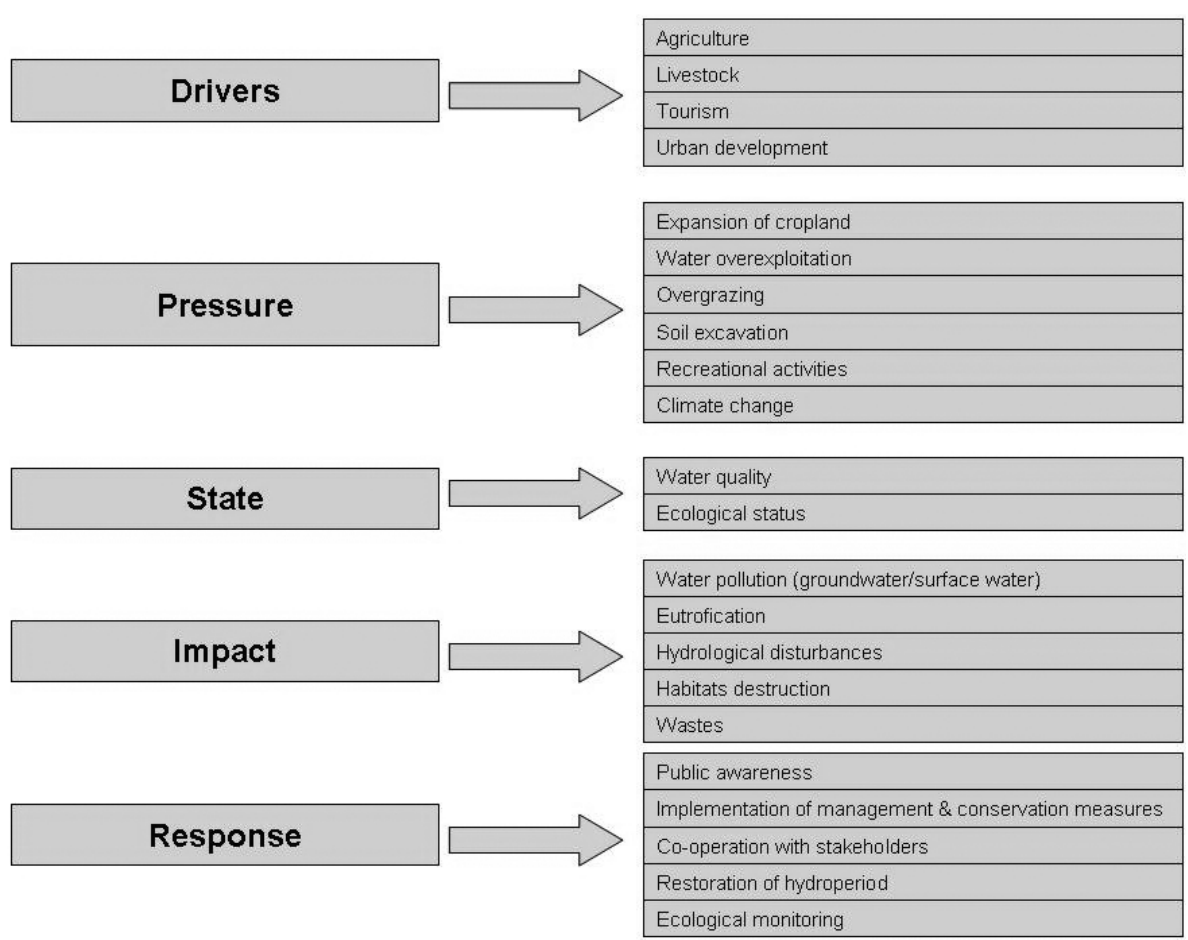

Fig. 6. DPSIR analysis for Greek MTPs 
Housing and road constructions for urban development often cause direct destruction of MTPs (Zacharias et al. 2007). Moreover, the significant number of tourists in combination with the various recreational activities that take place near the MTPs create unfavorable conditions especially in island MTPs, where the distribution of the habitat and of the touristic infrastructure usually coincides. In the Mediterranean region, some ponds have been deepened and connected with irrigation canals by farmers under water abstraction schemes, to create water reservoirs. Thus, the ponds can become permanent and also can be colonized by predators (common in irrigation channels) with destructive effects upon the endemic biota. The extraction of minerals (e.g., clay) which is a common practice in some Mediterranean countries, including Crete, can also change MTPs hydroperiod. Climate change which according to the IPCC scenarios will cause further reduction of precipitation and increase in mean annual temperature will also impact the MTPs by altering their hydroperiod. The flooding period of the ponds is one of the most important factors that mostly determines the ecological characteristics of the habitat and any important pressure on it may permanently change the habitat type. The ecological status of the MTPs changes with the potential water quality fluctuations, while the most widespread pressure remains public ignorance about the habitat value. Thus, the increase of public awareness, including policy makers and local authorities, should be of primary concern for the conservation of this habitat since random disasters could be prevented and local populations could apply management and restoration practices where needed. Another common response that must be applied in many cases is the restoration of hydroperiod that is very often affected either by human activities, or by climate change. In addition, ecological and livestock monitoring is essential to estimate the grazing capacity at each site, and to assess accurately the relevant impacts. Eventually, co-operation among the stakeholders, policy makers and environmental managers is necessary for designing and implementing the conservation and management strategies on a site specific basis.

\section{Acknowledgments}

This paper was supported by the LIFE Nature project "Actions for the conservation of Mediterranean Temporary Ponds in Crete".

\section{References}

Beja P. \& Alcazar R. 2003. - Conservation of Mediterranean temporary ponds under agricultural intensification: an evaluation using amphibians. Biol. Cons., 114, 317-326.

Bergmeier E. 2001. - Seasonal pools in the vegetation of in situ conservation required - Gavdos Greece. Bocconea, 13, 511-516.

Bergmeier E. \& Raus T. 1999. - Verbreitung und Einnischung von Arten der Isolto-Nanojuncetea in Griechenland. Mitt. Bad. Landesver. Naturkunde Naturschutz, 17, 463-479.

Bergmeier E. \& Abrahamczyk S. 2008 - Current and historical diversity and new records of wetland plants in Crete, Willdenowia, 38, in press.

Blaustein L. \& Schwartz S.S. 2001. - Why study ecology in temporary pools? J. Zool., 47 4, 303-312.

Beja P. \& Alcazar R. 2003. - Conservation of Mediterranean temporary ponds under agricultural intensification: An evaluation using amphibians. Biol. Cons., 114, 317-326.

Blaustein L. \& Schwartz S.S. 2001. - Why study ecology in temporary pools? J. Zool., 47, 303-312.

Brendonck L. \& Williams W.D. 2000. - Biodiversity in wetlands of dry regions (drylands). Biodiv. Wet. Assessm. Func. Conserv., 1, 181-194.

Dafis S., Papastergiadou E., Gewrgiou K., Mpampalonas T., Fewrgiadhs T., Papagewrgiou M., Lazaridou T. \& Tsiaoush B. 1997. Directive 92/43/EEC. The Wetland Project in Greece: Natura 2000 Network, Goulandris Natural History Museum - Greek Biotope/ Wetland Centre.

De Bolòs O., Masalles R.M., Ninot J.M. \& Vigo J. 1996. - A survey on the vegetation of Cephalonia (Ionian islands), Phytocoenologia, $26,81-123$.

Deil U. 2005. - A review on habitats, plant traits and vegetation of ephemeral wetlands - A global perspective, Phytocoenologia, 35, 533-705.

Dimitriou E., Karaouza I., Skoulikidis N. \& Zacharias I. 2006. Assessing the environmental status of Mediterranean temporary ponds in Greece. Ann. Limnol. - Int. J. Lim., 42, 33 - 41.

Dimitriou E., Bertahas I., Karaouzas I., Skoulikidis N., Colobari E., Moussoulis E. \& Diapoulis A. 2006. - 'Study of the anthropogenic impacts on the Mediterranean Temporary Ponds of Crete' in: Dimitriou E. and Diapoulis A. (Editors). 'Actions for the conservation of Mediterranean Temporary Ponds of Crete'. Final Report.

Elliott M. 2002. - The role of the DPSIR approach and conceptual models in marine environmental management: an example for offshore wind power, Mar. Poll. Bull., 44, iii - vii.

EUNIS - ECCHM - Factsheet for Mediterranean temporary ponds, European Nature Information System, EEA.

European Commission DG Environment. 2007 [Ed.]: Interpretation Manual of European union Habitats - EUR27. - 142pp., European Commission, Brussels).

Everts J.W. 1997. - Ecotoxicology for risk assessment in arid zones: Some key issues. Arch. Environ. Con. Tox., 32, 1-10.

Grillas, P., Gauthier P., Yavercovski N. \& Perennou C. 2004. - Mediterranean Temporary Pools, Volume 1 - Issues relating to conservation, functioning and management. Station biologique de la Tour du Valat.

King J.L. 1996. - Loss of diversity as a consequence of habitat destruction in California Vernal pools: Ecology, conservation, and management of vernal pool ecosystems proceedings from a Conference, Section II : The Plants, Animals, and Ecosystems-Ecology and Systematics, Status and Trends.

Krause W., Ludwig W. \& Seidel F. 1963. - Zur Kenntnis der Flora und Vegetation auf Serpentinstandorten des Balkans. 6. Vegetationsstudien in der Umgebung von Mantoudi (Euböa), Bot. Jahrb. Syst., 82, 337-403 + 7 tables (Beilagen).

Kristensen P. 2004. - The DPSIR framework, EEA.

Lahr J. 1997. - Ecotoxicology of organisms adapted to life in temporary freshwater ponds in arid and semi-arid regions, Arch. Environ. 
Con. Tox., 32, 50-57.

Lin T., Xue X. \& Lu C. 2007. - Analysis of Coastal Wetland Changes Using the "DPSIR" Model: A case study in Xiamen, China, Coast. Manage., 35, $289-303$.

Oberdorfer E. 1952. - Beitrag zur Kenntnis der nordägäischen Küstenvegetation, Vegetatio Acta Geobotanica, 3, 329-349.

OECD, (Organisation for economic Co-operation and Development), 1993. - Environmental indicators: basic concepts and terminology. Background paper No. 1. OECD, Paris.

Pirrone N., Trombino G., Cinnirela S., Algieri A., Bendoricchio G. \& Palmeri L. 2005. - The Driver-State-State-Impact-Response (DPSIR) approach for integrated catchment - coastal zone management: preliminary application to the Po catchment - Adriatic Sea coastal zone system, Reg. Environ. Change, 5, 111 - 137.

Rhazi M., Grillas P., Mounirou Toure L. \& Tan H. 2001. - Impact of land use in catchment and human activities on water, sediment and vegetation of Mediterranean temporary polls, Life Sci., 324, $165-177$.
Sarika-Hatzinikolaou M., Yannitsaros A. \& Babalonas D. 2003. The macrophytic vegetation of seven aquatic ecosystems of Epirus (NW Greece). Phytocoenologia, 35, 93-151.

Serrano L. \& Serrano L. 1996. - Influence of groundwater exploitation for urban water supply on Temporary Ponds from Don】na National Park (SW Spain). J. Environ. Manage., 46(3), 229-238.

Smeets E. \& Weterings R. 1999. - Environmental indicators: Typology and overview, European Environmental Agency, Technical Report $\mathrm{n}^{\circ} 25$.

Stamati F. \& Nikolaidis N. 2006. - Technical report: Hydrology and Geochemistry of Mediterranean Temporary Ponds (MTP) of Crete. Actions for the conservation of Mediterranean Temporary Ponds of western Crete.

Walmsley J.J. 2002. - Framework for Measuring Sustainable Development in Catchment Systems, Environ. Manage., 29, 195-206.

Zacharias I., Dimitriou E., Dekker A. \& Dorsman E. 2007. - Overview of temporary ponds in the Mediterranean region: Threats, management and conservation issues, J. Environ. Biol., 28(1), 1-9. 